\title{
Japan's laws on recombinant DNA tie researchers' hands
}

Japanese scientists face a year in jail and a ¥1 million (about \$9,000) fine if they violate the extensive rules their government now has in place for using recombinant DNA technology. Some researchers say they are worried the restrictions and new local regulations will set back Japanese research in related fields.

The backdrop to the debate is a public sentiment that frowns on genetic modification. "There is an allergy to anything relating to recombinant DNA technology, especially in agriculture and food," says Hideo Shinagawa, a microbiologist at Osaka University.

Concerns intensified in September 2003 with the implementation of the Cartagena Protocol on Biosafety, which attempts to ensure the safe shipping of genetically modified organisms. Japan already had guidelines on recombinant DNA research, but after signing the protocol, it turned the guidelines into binding laws, effective as of February.

"This is going to have a big impact on researchers whether they are doing basic science or applied research with plants and microbes," says Hiroshi Kamada, a molecular biologist at the University of Tsukuba. "Research is going to move much more slowly." Hamada predicts that scientists wanting to do such research will be forced to leave Japan. "There are so many things that remain unclear that many people will just stop doing this kind of research," he says.

The law sets a standard for DNA sources and stipulates that researchers must apply through their institutions or to the central government to carry out recombinant DNA work. Some say the restrictions are excessive. "If you make a virus with a small piece of DNA, even linker DNA, [the experiment] needs to be approved-which is ridiculous," says Yoshihiro Kawaoka, a virologist who splits his time between the University of Wisconsin and the University of Tokyo.

Under the new law, requirements on the labeling of research materials for shipping have become more burdensome (Nature 428, 6; 2004). Sending genetically altered viruses, bacteria and even plasmids will require more paperwork and some negotiation with the post office, says Shinagawa.

But some researchers and government officials say the new law has made things easier. "Everything in the application process is much clearer and more straightforward," says Tadahito Kanda, a virologist at the National Institute of Infectious Diseases. Some restrictions have been dropped because of pressure from scientists. "The only people that will

really be affected are those who weren't following the guidelines previously," Kanda says.

Shinagawa agrees that many things have become less bureaucratic. For example, requirements that every room dealing with recombinant DNA have an autoclave and special safety cabinets have been relaxed so that only one autoclave and cabinet per building is necessary.

But researchers are also concerned because some local governments are going beyond the

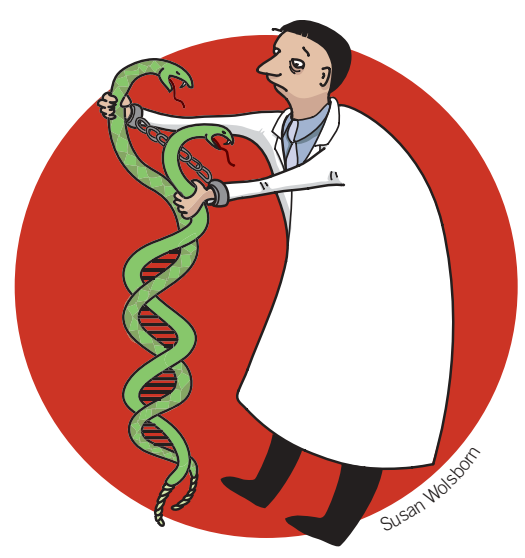

law to add their own restrictions. In March Hokkaido, Japan's northern island, put into effect its own guidelines asking researchers to steer clear of field trials with genetically modified plants. Similar ordinances are under consideration in the Shiga and Ibaragi regions. "In Japan, if one region makes an ordinance, movements to create the same ordinance in other regions will soon become active," says Kamada.

Shinagawa and Kamada are part of a sevenperson committee in Japan's Science Council that is trying to dissuade local governments from adding more restrictions. Other researchers are also taking action. On 30 April, 49 members of the Japanese Society of Breeding sent a letter to Hokkaido's governor urging her not to make binding rules against genetic modification, particularly those requiring applications at the local level. "The local government doesn't have the capacity to process applications," says Kazuo Watanabe, a geneticist at Tsukuba University and one of the petitioners. "That means that certain research projects there could be brought to a halt."

David Cyranoski, Tokyo

\section{Lax security at 'hot' labs draws fire}

Community groups protesting the

proliferation of biodefense 'hot labs' conjure up scenarios of lax security, accidental infections and dangerous microbes escaping into the neighborhood to bolster their case. A previously unreleased report on inspections of existing labs suggests that only luck has kept those scenarios from becoming reality.

In April, the Office of Inspector General (OIG) at the US Department of Health and Human Services reported problems with security, database access and record keeping at 11 unnamed university labs. The inspections were carried out in 2002 but the report, completed in 2003, was not made public.

In response to numerous requests, particularly from the academic community, however, the agency released a summary, citing "serious weaknesses that compromised the security of select agents at all of the universities reviewed."

The labs handle 39 'select agents' - toxins, viruses and other potential bioweapons such as anthrax. The inspectors found unlocked security doors, easy access to lab keys and scant attention to security badges, leaving labs vulnerable to intruders. The report also cited problems with sensitive data. In one case, a worker circulated an email with the lab's select agent registry to people outside the university. Researchers were also not required to maintain select agent inventories. In some cases, they did not document to whom they shipped those agents.

Under the US PATRIOT Act, institutions handling select agents were required to register with the US Centers for Disease Control and Prevention (CDC) and meet strict safety standards by March 2003. But at the time of the inspections, many labs had just begun implementing the measures, says Ted Jones, acting director of the CDC's select agent program. Jones says new inspections would find a very different system. "I would describe it as a sea change," he says.

Jonathan King, a researcher at the Massachusetts Institute of Technology, says he draws little comfort from the PATRIOT Act provisions. Secrecy provisions in the act will only make it more difficult for communities to assess risks from the agents at the labs, says King, who is one of more than 150 academics in the Boston area opposing a plan to build a national bio-containment lab in the city. The US National Institutes of Health's budget calls for 11 such labs at some of the country's premier research institutions (Nat. Med. 9, 805; 2003).

Tinker Ready, Boston 